\title{
Clinical and ethical perspectives on brain death
}

\author{
This article was published in the following Dove Press journal: \\ Medicolegal and Bioethics \\ II September 2015 \\ Number of times this article has been viewed
}

\section{Michael Nair-Collins \\ Behavioral Sciences and Social Medicine, Florida State University College of Medicine, Tallahassee, FL, USA}

\begin{abstract}
Death determined by neurological criteria, or brain death, is an accepted legal standard for death throughout much of the world. However, brain death has also been a source of controversy ever since its inception, and recently it has been subjected to increased scrutiny, both in academia and in the public domain. The purpose of this paper is to provide an overview of the literature on brain death, with a focus on clinical and ethical perspectives on the topic. To provide context, the history and legal standards, pathophysiology, and clinical diagnostic standards for brain death are reviewed in this paper. Controversies regarding the diagnostic tests and pathophysiology of brain death, the validity of neurological criteria for death, the relationship between brain death and organ transplantation, and several recent legal cases involving brain death in the USA are also reviewed.
\end{abstract}

Keywords: brain death, total brain failure, death determined by neurological criteria, organ transplantation, dead donor rule, determination of death, organ donation

\section{Introduction}

The declaration of death by neurological criteria is an accepted medical practice throughout most of the world ${ }^{1}$ and yet both public and academic controversies persist. ${ }^{2-5}$ The purpose of this paper is to provide an overview of the literature on brain death, focusing on clinical and ethical perspectives on the topic. To provide context, the history and legal standards, pathophysiology, and clinical diagnostic standards for brain death, followed by a discussion of clinical and ethical controversies, were reviewed with a focus on recent developments in the literature.

\section{History of brain death}

The story of brain death begins with changing medical practices in the 1950s and 1960s (see Stevens, ${ }^{6}$ Jonsen, ${ }^{7}$ Pernick, ${ }^{8}$ De Georgia, ${ }^{9}$ and Belkin ${ }^{10,11}$ for detailed historical accounts and analyses of the development of the concept of brain death). In this era, the mechanical ventilator came into widespread use, which allowed physicians to support the physiological functioning of severely neurologically injured patients who lacked a respiratory drive and thus would otherwise have died within minutes from lack of oxygen. Almost immediately, physicians had ethical concerns about maintaining the physiological functioning of patients they believed to be "hopelessly unconscious", ${ }^{12}$ or in a state of coma dépassé (beyond coma). ${ }^{13}$ This included concerns about the just use of limited resources, financial burdens to families and hospitals, and the emotional toll on families whose grieving process seemed to be held in limbo, with a family member who was not yet dead and buried, but in a hopeless condition from which
Correspondence: Michael Nair-Collin Behavioral Sciences and Social Medicine, Florida State University College of Medicine, III 5 West Call Street,

Tallahassee, FL 32306, USA

Tel +l 8506456564

Email michael.nair-collins@med.fsu.edu 
he or she could not recover. ${ }^{14}$ Further, this was an era prior to the seminal Karen Ann Quinlan case, ${ }^{15}$ which set a legal precedent in the USA for the permissibility of removing life-sustaining treatment. Prior to this case, there was legal uncertainty, at least among physicians, as to whether removing life-sustaining treatment would be considered legally culpable homicide.

At the same time, the nascent field of human organ transplantation was beginning to show some promise, with early renal, hepatic, and cardiac transplantations taking place. Since human organs are highly sensitive to ischemic damage, donor organs that are perfused with oxygenated blood right up until the moment of retrieval - that is, organs that are removed from a body with continuing circulation - provide the greatest opportunity for successful transplantation. Thus, due to their continued physiological functioning combined with permanent unconsciousness, patients in a "hopeless" or irreversible coma seemed to be ideal organ donors.

To address this array of concerns, physicians and scholars began to discuss whether patients in an irreversible coma should be considered to be dead already, prior to discontinuing the mechanical ventilator. In 1968, an Ad Hoc Committee of the Harvard Medical School published a set of guidelines defining the condition of irreversible coma, along with clinical guidelines for its diagnosis, and asserted that irreversible coma should be considered "a new criterion for death". ${ }^{14}$ This paper was very influential, and within only a few years, several US states began to develop laws permitting physicians to declare patients on mechanical ventilators to be dead based on the absence of brain function. However, not all states did so, creating legal ambiguity since the very same patient could be dead in one state but alive in another. This prompted the US President's Commission for the Study of Ethical Issues in Medicine and Biomedical and Behavioral Research to address the question as their first item. ${ }^{16}$

Largely endorsing what came to be known as "the Harvard criteria", the President's Commission agreed that patients with lack of brain function should be considered to be dead. The President's Commission was also instrumental in developing the Uniform Determination of Death Act, which was endorsed by the National Conference of Commissioners on Uniform States Laws, the American Medical Association, and the American Bar Association, and states: "An individual who has sustained either (1) irreversible cessation of circulatory and respiratory functions or (2) irreversible cessation of all functions of the entire brain, including the brain stem, is dead". This model law, or something very close to it, was subsequently adopted by all 50 states through either legislative or judicial action, ${ }^{17}$ and at least 70 countries of the world now endorse the practice of determining death by neurological criteria, though with some variation in both law and practice. ${ }^{1}$

Although the practice of determining death by (some) neurological criterion has found wide acceptance in much of the world, not all nations endorse the whole brain concept of death, in which all functions of the entire brain are required for the diagnosis. For example, the United Kingdom endorses a brainstem death concept, in which lack of all functions of the brainstem is considered to be sufficient for death. ${ }^{18,19}$ Japan initially resisted the concept of whole-brain death, although has now also endorsed whole-brain death criteria. $^{20,21}$ An international working group, in collaboration with the World Health Organization, is now working on developing international consensus guidelines for the determination of death. ${ }^{22}$

\section{Pathophysiology and diagnostic tests}

Brain death can have a number of etiologies, though the basic pathophysiology is a rather simple matter of fluid dynamics (for overviews of the physiological aspects of brain death, see Smith, ${ }^{23}$ Smith and Vyas, ${ }^{24}$ and chapter 3 of the 2008 report of the US President's Council on Bioethics ${ }^{25}$ ). Any insult or injury that causes intracranial pressure (ICP) to increase at a rate and degree that overwhelms the ability of the cerebrospinal fluid to shunt out of the cranium (which helps to maintain normal ICP) can result in brain death, such as acute hemorrhage, hypoxic-ischemic encephalopathy, and metabolic disturbances (eg, liver failure). When ICP increases quickly enough and to a degree that begins to resist the driving force of blood entering the skull, cerebral perfusion begins to decrease. This decrease, in turn, yields cellular damage and hence edema (swelling) when intracellular contents extrude into the extracellular space. This swelling results in further increased ICP, which further decreases cerebral perfusion, and so on in a positive feedback cycle. The outcome of that cycle is when ICP exceeds mean arterial pressure, thus completely resisting the driving force of blood entering the skull, yielding intracranial circulatory arrest and global cerebral anoxia. This is often accompanied by brain herniation, usually centrally and downward through the foramen magnum, compressing and herniating the brainstem. The process of anoxic injury, edema, and herniation moves in a rostral-to-caudal direction, with the lower brainstem being the final anatomic area affected. (However, some have argued that not all cases of suspected brain death follow this typical 
pattern, which would significantly complicate interpretation of the standard clinical diagnostic tests. ${ }^{26}$ )

The core medical diagnostic tests for brain death are fairly settled, though some aspects also remain a matter of controversy. The diagnosis involves three cardinal features: unresponsiveness to pain or other stimuli (with the exception of reflexes mediated solely through the spinal cord); the absence of all cranial nerve reflexes; and apnea, in the setting of a known cause of coma and with potential confounds (eg, intoxication, hypothermia, and acid-base disturbances) ruled out as an explanation for the unresponsiveness. ${ }^{27,28}$ Given the pathophysiology of brain death, in which sequential dysfunction due to anoxic injury moves in a rostral-caudal direction ending at the lower brainstem, these tests, prima facie, make logical sense, because they all test brainstem function. Unresponsiveness to pain or other stimuli primarily tests the reticular activating system originating at the pontomedullary junction; cranial nerve reflexes originate in a variety of nuclei throughout the brainstem; and the apnea test challenges medullary respiratory drive centers by increasing carbon dioxide in the blood. Furthermore, the cardinal features of unresponsiveness, brainstem areflexia, and apnea, in the absence of confounds and the presence of a known cause of coma, are the core elements of accepted diagnostic tests around the world, ${ }^{1}$ even for brainstem death, since they test for the loss of functional abilities of the brainstem.

\section{Controversies surrounding the tests and pathophysiology of brain death}

Persistent controversies remain around the clinical diagnosis of brain death. Some represent relatively minor concerns regarding the details of clinical practices, but fundamentally accept the validity of the concept and diagnosis of brain death. These include discussions on whether clinical tests need to be repeated, ${ }^{29}$ whether to use ancillary confirmatory tests such as imaging or electroencephalography, ${ }^{30}$ and the type of training of the clinician permitted to make the diagnosis. ${ }^{1,31}$ On the other hand, other controversies reflect more fundamental concerns.

As described in the history of brain death section, the whole brain concept of death, which is codified in US law through state statutes and judicial decisions that effectively embody the Uniform Determination of Death Act, requires the irreversible cessation of all functions of the entire brain. However, patients who meet the accepted diagnostic criteria for brain death can sometimes have some preserved neurological functioning, particularly hypothalamic functions such as the regulation of free water in the bloodstream (osmoregulation). In a recent review of the clinical literature, Nair-Collins et al ${ }^{12}$ found evidence suggesting preservation of hypothalamic function in a substantial proportion of patients declared dead by neurologic criteria. Approximately half of the patients reported in the literature showed evidence suggesting osmoregulation via the regulated secretion of vasopressin (anti-diuretic hormone). A substantial proportion of patients also demonstrated a preserved endocrine profile by secreting hypophysiotropic hormones (originating in the hypothalamus) that regulate the secretion of anterior pituitary hormones. Furthermore, some patients who satisfy accepted diagnostic tests for brain death maintain organized cortical electrical activity and, less commonly, preserved sensory evoked potentials. ${ }^{33}$ These findings cast doubt on the reliability of standard diagnostic testing procedures to accurately identify those patients who have suffered from the irreversible cessation of all functions of the entire brain, which is required by any state law based on the Uniform Determination of Death Act.

Another area of controversy is the apnea test, which is performed last in suspected brain death, after unresponsiveness and cranial nerve areflexia have been demonstrated. In the apnea test, the patient is oxygenated with $100 \%$ oxygen, the ventilator is switched off, and then physicians watch for signs of any inspiratory effort. As time passes, carbon dioxide builds up in the patient's blood, and elevated levels of carbon dioxide (hypercarbia) would normally stimulate the respiratory centers of the lower brainstem to expand the thoracic cavity. After several minutes, if no inspiratory effort is taken, then arterial blood gases are measured and the ventilator is switched back on. If the pressure of carbon dioxide in the arteries is $>60 \mathrm{mmHg}$ (or if it is $>20 \mathrm{mmHg}$ greater than baseline, tested prior to the apnea test), and if there have been no inspiratory efforts, then the patient is considered as apneic. ${ }^{28}$

This test has been criticized on a number of grounds. First, there are a number of potential confounding conditions which can invalidate interpretation of the apnea test. Some are routinely considered, such as hypotension, hypoxia, metabolic abnormalities, and pharmacologic effects. However, high cervical spinal cord injury and endocrine dysfunction can also invalidate the apnea test, and these confounds are not as often considered in the diagnosis, though they can be common in patients with suspected brain death. ${ }^{34}$ Perhaps more concerning, hypercarbia (which is deliberately induced in the apnea test) is known to increase ICP and therefore can worsen ischemic injury to the brain, potentially contributing to herniation, and thus can be dangerous to a recently injured 
brain. ${ }^{34-36}$ "Indeed", Joffe et al wrote, "it is reasonable to suggest that the apnea test itself can result in failing the apnea test, creating a self-fulfilling prophecy". ${ }^{34}$ Finally, although eupneic inspiratory efforts are stimulated by hypercarbia in the setting of normal physiology, in the context of the specific pathophysiology of a cascade of rostral-caudal dysfunction in which the lower medulla will be the final anatomic area to be compromised, the appropriate stimulus would be hypoxia (not hypercarbia), because hypoxia stimulates the lower medulla-mediated gasping reflex. ${ }^{34}$

Some concerns regarding the safety of the apnea test have been discussed in the literature. ${ }^{37-41}$ For example, in a review of a large series of brain death determinations at a single institution, Wijdicks et al wrote "The apnea test is a fixture in brain death determination, but there is a perceived concern about the safety of the procedure". ${ }^{38}$ However, they wrote, "We may conclude from our study that the apnea testto passively increase [arterial carbon dioxide pressure] - is a safe and simple procedure". ${ }^{38}$ In this study, the safety of the apnea test was operationalized in terms of the absence of major complications such as cardiac arrest or pneumothorax, but did not address the concern that hypercarbia can increase ICP nor that hypoxia rather than hypercarbia is the more appropriate stimulus. Other authors have rejected the argument that the apnea test can contribute to its own positive outcome on the grounds that it has not been demonstrated that the apnea test causes the final infarction of the lower brainstem. ${ }^{37}$

A final clinical controversy regards the irreversibility of the cessation of function. When the concept of brain death was first promulgated in the 1960s-1980s, it was believed that the entire brain would be quickly anatomically destroyed. ${ }^{16}$ However, this is not the case. A more recent pathology study found that brainstem and higher brain structures showed moderate to severe ischemic changes in only approximately $34 \%-68 \%$ of patients with brain death, with variability in different brain areas; ${ }^{42}$ thus, the lack of anatomical destruction of the brainstem and cortex is compatible with the diagnosis of brain death. As mentioned above, neuroendocrine function, electroencephalographic activity, and preserved sensory evoked potentials are also compatible with standard diagnostic tests, and clinical tests for minimally preserved consciousness in the setting of unresponsiveness are extremely difficult to empirically validate. ${ }^{43}$ Furthermore, since intracranial circulatory arrest is not entirely complete in all cases, ${ }^{44}$ since ICP decreases after its acute trigger resolves, and since the arteries supplying the brain can remain patent, it may be physiologically possible that some areas of neural tissue can remain viable through something like a global ischemic penumbra. ${ }^{35}$ As in stroke pathophysiology, the concept of ischemic penumbra refers to a condition in which blood flow diminishes to a degree that is incompatible with clinically detectable functioning but is sufficient to maintain the physiological viability of the tissue for some time. However, there have been no sustained research efforts on this issue, and cardiovascular collapse following the diagnosis of brain death is a self-fulfilling prophecy since the patient will either become an organ donor or mechanical support will be removed; ${ }^{45}$ therefore, it is unknown whether this is a realistic possibility or mere speculation.

\section{Controversies surrounding the validity of neurological criteria for death}

Although medical practices surrounding the declaration of death by neurological criteria are apparently well accepted throughout much of the world, the scientific and philosophical validity of "whole-brain death" has been a matter of controversy ever since its inception, even assuming that the irreversible cessation of all functions of the entire brain can be reliably diagnosed. ${ }^{46,47}$ In recent years, the debate has seen renewed vigor. $^{25,48-51}$ This unusual situation of a mostly accepted practice combined with persistent dispute about its moral, conceptual, and scientific foundations has been described as a "superficial and fragile consensus", 52 as "well settled yet still unresolved", 53 and the concept of brain death as being "too flawed to endure, too ingrained to abandon". ${ }^{54}$ (For more extensive reviews of the philosophical and ethical literature on brain death, see DeGrazia ${ }^{55}$ and Nair-Collins. ${ }^{51}$ )

Irreversible coma was posed as a new criterion for death as a means to address social and legal concerns, though in the absence of any systematic philosophical or scientific justification. It was only after the practice became fairly widespread that scientific and philosophical justifications were proposed in its defense. Some scholars argued that brain death was a legitimate criterion for death because, although the body is biologically alive, the person has ceased to exist due to irreversible unconsciousness, and thus death can legitimately be declared.$^{56}$ This view also implies that death can be declared in other conditions in which consciousness seems impossible due to the dysfunction, destruction, or the absence of cortical or "higher brain" regions, such as anencephaly and the vegetative state, and thus this view came to be known as the "higher brain theory of death". 
Within the higher-brain camp, there are some technical differences in views. For example, although Green and Wikler ${ }^{56}$ argue that brain death is death because the person has died (even though the body is biologically alive), Veatch argues that personhood is irrelevant to the debate, ${ }^{57}$ because there can be minimally conscious non-persons who are alive on his view, since he endorses a Lockean view of personhood that requires fairly substantial cognitive capacities including self-awareness, not mere sentience. On the other hand, McMahan identifies personhood with the embodied capacity for consciousness, and so would not recognize a living minimally conscious non-person. ${ }^{58} \mathrm{Lizza}^{48}$ argues that Green and Wikler, ${ }^{56}$ Veatch, ${ }^{57}$ and others endorse a qualitative or functionalist account of persons, which he opposes with his non-reductive, substantive view of persons as substances that have both biological and psychological characteristics. In spite of all of these rather technical differences, however, they would all agree that in brain death the body is biologically alive but the individual (or person) is dead.

Although perhaps philosophically defensible as a theory of when personhood ceases, this view is difficult to justify in practice for a number of reasons. First, it seems to address the wrong question. Death is a biological phenomenon, and furthermore the expertise of medicine lies in biology and related areas, not in defining the essential nature of personhood and the self. Certainly the possibility or impossibility of preserved consciousness is ethically relevant for whether to withdraw life-sustaining treatment or allow organ procurement, but this is not the same as identifying whether the patient is already dead. Furthermore, concepts of personhood are fundamental philosophical concepts rooted in large-scale philosophical or religious worldviews, and they implicate questions about which reasonable people can reasonably disagree. In democratic, pluralistic societies, it seems misguided to attempt to enforce a particular normative philosophical view of personhood as official social policy.

On a more practical level, diagnosing the lack of consciousness is fraught with difficulty, and there is a consistent $30 \%-40 \%$ false positive misdiagnosis rate for the vegetative state. ${ }^{59}$ This would add too much uncertainty to a matter as important as determining death. Finally, many people are convinced by the simple practical argument that if the higher brain theory of death was correct, then spontaneously breathing bodies (as in the vegetative state) would be dead already, which implies that it would usually be permissible to bury such bodies. But few are prepared to bury sponta- neously breathing bodies. This suggests that most people acknowledge that there is a difference between lack of personhood or lack of consciousness, and death. ${ }^{16}$

The mainstream, prevailing view holds that death is a biological phenomenon, not a social construction or a theory of personhood. ${ }^{22,25,60}$ The most influential treatment of these issues $^{60,61}$ consists of a sequential process of defining the concept of "death" (a philosophical task), then outlining the physiological criteria that would satisfy that definition (a combined philosophical and medical task), and finally devising diagnostic tests that can be used to identify when the physiological criteria have occurred (a medical task; the accepted diagnostic tests and their controversies were outlined in the preceding section).

The standard theory holds that biological death is the irreversible cessation of the integrative functioning of the organism as a whole in its capacity to maintain internal physiological stability (homeostasis) and resist entropy and disintegration. ${ }^{16,60-62}$ On this view, death is an event (rather than a process), something like a thermodynamic point of no return, which separates the processes of homeostatic maintenance and resistance of entropy from increasing entropy and disintegration. Brain death was proposed as an acceptable physiological criterion for biological death based on the idea that the brain is the "critical system" for the organism as a whole. On this view, the brain serves as the central, integrating unifier, directing the various processes and mechanisms of subsystems toward a unified maintenance of homeostasis for the organism as a whole, without which the organism could not engage in its life-characterizing processes. As Bernat et al wrote, "This criterion [of brain death] is perfectly correlated with the permanent cessation of functioning of the organism as a whole", ${ }^{61}$ and as Bernat later emphasized, "With the loss of the critical system [the brain], the organism loses its life-characterizing processes, and entropy (disorder) inevitably increases". ${ }^{62}$

Assuming this theory of biological death, the claim that brain-dead patients are dead has been subjected to what some consider a definitive refutation by empirical evidence. Patients who meet the standard diagnostic tests for brain death can engage in a wealth of homeostasis-maintaining and integrative physiological functions, which together manifest a clear anti-entropic capacity of the organism as a whole, and thus biological life; and they can do so for many years. If maintained with common medical treatments such as mechanical ventilation, such patients can engage in gas exchange at the alveoli, cellular respiration, nutrition, wound 
healing, febrile responses to infection, tachycardic, hypertensive, and endocrine stress responses to incision, and even such dramatic examples as growth and sexual maturation in children and the gestation of healthy fetuses in pregnant women..$^{33,50,51,63-68}$ Although such patients are dependent on technology without which the patient would be dead, in and of itself this does not mean that such patients are already dead, otherwise any other patient who is dependent on a ventilator, dialysis, a pacemaker, or even insulin for that matter, would also be dead.

Proponents of the mainstream view responded to this challenge by changing the concept of death from the irreversible cessation of the functioning of the organism as a whole to the irreversible cessation of the critical functions of the organism as a whole, ${ }^{60,69}$ where "critical" refers to those functions that are "necessary for the maintenance of life, health, and unity of the organism". ${ }^{69}$ The purpose of this change was to rule out those functions that are preserved in a brain-dead patient as not relevant. However, this move is ad hoc: It was designed solely to protect from empirical refutation the claim that brain death is death. ${ }^{68}$ Furthermore, when combined with the assertion that brain death is its criterion, this view implies that cellular respiration, nutrition, wound healing, etc are not critical functions "necessary for the life, health, and unity of the organism", which is surely false, thus yielding a reductio ad absurdum.

Because this physiological evidence has become so well known, the US President's Council on Bioethics re-examined the issue, and acknowledged that brain-dead patients maintain physiologic stability and resist entropy:

Nonetheless, something like health is still present in the body of a patient with total brain failure [brain death]. This can be seen clearly in the 'donor management' procedures ... [that] aim to maintain the body in a relatively stable state of homeostasis [...] Thus, there is some degree of somatically integrated activity that persists in the bodies of patients who have been declared dead according to the neurological standard. ${ }^{25}$

However, the Council did not conclude that such patients were alive; instead, they proposed a new theory of biological death that was designed specifically to enable the conclusion that patients with brain death (total brain failure, in their terminology) are dead. The Council proposed that what it means to be a living organism is to engage in "vital work" in its exchanges with the environment, which is manifested by receptivity to stimuli, the ability to act on the world to selectively obtain what it needs, and a "basic felt need" that drives the organism to obtain what it needs. ${ }^{25}$ In more operational terms they conclude

If there are no signs of consciousness and if spontaneous breathing is absent and if the best clinical judgment is that these neurophysiological facts cannot be reversed, [the Council would] conclude that a once-living patient has now died. ${ }^{25}$

This new defense of brain death has been criticized on multiple grounds. Perhaps most importantly, the Council offered no reasons as to why the well-accepted theory of biological death explained in terms of homeostasis and entropy resistance is flawed or should be revised, and the sole purpose of the new theory is to yield a pre-determined conclusion. But scientific theories are not simply abandoned because they do not yield one's favored conclusions. ${ }^{68}$ Second, neither permanent loss of consciousness nor loss of the capacity for spontaneous breathing, by itself, is sufficient for death. There is no justification for concluding that the combination is sufficient for death, particularly when so many other biological functions are maintained, and this is a non-sequitur. ${ }^{70}$ Finally, because the Council wanted to conclude that patients in a vegetative state or anencephaly were biologically alive, they defined key terms, such as "act upon the world" and "basic felt need" in such a way that brain-dead patients satisfy the theory's requirements for being alive anyway. Although they are not conscious and do not make spontaneous inspiratory efforts, such patients nonetheless exhibit the "vital work" of an organism by being receptive to and acting upon their environment through fighting infections, healing wounds, maintaining body temperature, metabolizing nutritive products and generating waste, exchanging gases through the lungs, and so on. ${ }^{51,70-72}$

As mentioned above, the argument that brain death is not the same as biological death has been around since the beginning of these debates. ${ }^{57}$ Some have argued from the start that at its core, this is not a biological question, but rather is one for social policy or is one about philosophical conceptions of the essential nature of humanity. ${ }^{46}$ In that tradition, several scholars are now arguing that brain death is a social construction $^{2}$ or that it need not match up to any particular biological conception of death. ${ }^{73,74}$ Others have argued that in this specific context, the word "death" has evolved to take on a social or moral (rather than biological) meaning, and it means something like "morally permissible to remove organs", even though the brain dead body is biologically alive ${ }^{57,75}$ Finally, some scholars argue that neurological criteria for death represent a "legal fiction". ${ }^{71,76}$ Though, notably, 
Shah and colleagues ${ }^{71,76}$ do not claim that the legal fiction is justifiable public policy for the long term, but rather represents a second-best and temporary policy solution. This contrasts with the previously cited authors who take the social construction of brain death to be a legitimate and sustainable public policy. On this family of views, the use of brain death as a legal criterion for death represents a social decision rather than biomedical fact.

\section{The dead donor rule and consent for organ procurement}

The concept of brain death is inextricably linked to organ transplantation. One of the motivations that the Harvard Committee endorsed for adopting irreversible coma as a new criterion for death is that doing so would facilitate organ procurement from these patients. ${ }^{14}$ To this day, the majority of organs are removed from brain-dead donors. Organs are removed while the donor remains on the ventilator and with a spontaneously beating heart (thus they are sometimes referred to as "heart-beating donors"). However, because such donors are considered to be "dead", it is alleged that organ procurement practice is consistent with the "dead donor rule", which is an informal ethical and legal constraint that prohibits causing death by organ removal. ${ }^{77}$

The standard defense of the dead donor rule holds that it is a deontological constraint that forbids killing one person by organ removal in order to save others. This constraint holds regardless of whether the patient is unconscious, severely debilitated, or near death, and regardless of whether the patient has consented to being killed by organ removal. Described as "a centerpiece of the social order's commitment to respect for persons and human life", ${ }^{77}$ this rule has been defended on the grounds of respect for persons ${ }^{77}$ and as a manifestation of traditional Hippocratic medical ethics according to which doctors must not kill. ${ }^{77,78}$ On this view, if brain death is not death, then heart-beating organ removal is ethically impermissible. This is the view that was taken by the President's Council:

If indeed it is the case that there is no solid scientific or philosophical rationale for the current 'whole brain standard,' then the only ethical course is to stop procuring organs from heart-beating individuals. ${ }^{25}$

And indeed both Gomez-Lobo and Pellegrino, who held the minority view on the President's Council, did conclude that heart-beating organ procurement is impermissible because they did not accept the majority view's defense of total brain failure as equivalent to death, and thus concluded that heart-beating organ retrieval violates the dead donor rule. ${ }^{25}$

On the other hand, others argue that doctors' causing death is not always wrong, and indeed, that doctors permissibly cause death in other circumstances routinely, through the withdrawal of life-sustaining treatment. ${ }^{79,80}$ Furthermore, these authors argue that the dead donor rule is violated already, since brain-dead donors are alive. However, lethal organ procurement is permissible, they argue, when it is tied to a valid decision to withdraw life-sustaining treatment and with a valid consent for lethal organ removal. ${ }^{50,81,82}$ On this view, current organ procurement practices are ethically objectionable because of the lack of valid informed consent (since donors are not informed that organ retrieval causes death), but heart-beating organ removal would be ethically unproblematic if valid consent were obtained.

Proponents of the mainstream view have responded to this challenge by arguing that the dead donor rule is necessary to preserve public trust in medicine and the organ transplantation enterprise, and this trust is necessary to preserve organ donation rates in the voluntary, opt-in system of organ donation in the USA. ${ }^{83}$ This response is not based on the traditional ethical motivation for the dead donor rule as a deontological prohibition against killing. Instead, this defense of the dead donor rule is a version of rule consequentialism, in which a general rule is proposed on the grounds that, on the whole, following the rule will have better consequences than not following it. From this perspective, empirical evidence regarding public opinions about the dead donor rule is relevant for evaluating the cogency of the argument.

In a recent national survey, Nair-Collins et $\mathrm{al}^{84}$ presented US residents $(n=1,096)$ with a hypothetical scenario of organ procurement that violated the dead donor rule. A patient was described as being in an irreversible coma but biologically alive, and organ procurement was described as causing the biological death of the donor. In this survey, $71 \%$ of participants agreed that lethal organ removal should be legally permitted, and $67 \%$ agreed that they would want to donate organs if they were in a similar situation. Furthermore, most (but not all) participants who were willing to donate organs "after death" were also willing to donate in irreversible coma with organ retrieval causing death, and willingness to donate after death correlated positively with willingness to donate in irreversible coma. ${ }^{84}$ This survey suggests that many members of the US public would support organ procurement in situations that violate the dead donor rule, casting doubt on the assertion that the dead donor rule is necessary to preserve trust and organ donation rates (at least in the USA), and 
thus on the cogency of Bernat's ${ }^{83}$ defense of the status quo. Nonetheless, there remains a substantial gap between the number of donated organs and the number of people who could benefit from them, ${ }^{85}$ so any proposed changes to organ procurement practices should take into account potentially harmful consequences, particularly an exacerbation of the gap between demand and supply of organs.

Although the dead donor rule is a matter of debate in academia, it has never been formally and explicitly abandoned in practice in any nation. In other words, the official stance of organ procurement organizations throughout the world is that organ procurement does not cause the death of the donor. This creates additional ethical concerns about the validity of consents to donate organs. If the scientific criticisms of brain death discussed above are correct, then organ procurement causes the (biological) death of the donor, but this is not disclosed to prospective donors or their surrogates. At the very least, it is an undisputed fact that there is significant academic debate about whether heart-beating organ procurement kills the donor, and some have argued that failing to disclose this uncontested fact to the general public, to potential donors making the decision whether to register their consent to donate, and to families making surrogate decisions, is itself ethically problematic. ${ }^{51}$

There is substantial confusion among the public about both brain death and organ procurement. In a recent review of the international literature on public beliefs and attitudes, Shah et $\mathrm{al}^{86}$ found misunderstanding about basic clinical facts about brain death, about the legal status of brain death, and about the process of organ procurement, particularly that it takes place while the donor remains on the ventilator with a beating heart. Furthermore, a quantitative study of the websites of organ procurement organizations and internet consent forms for organ donation in the USA revealed a nearly complete lack of information that was recommended for informed consent for organ donation by the US Department of Health and Human Services Advisory Committee on Organ Transplantations. ${ }^{87}$ For example, none of the websites provided information on criteria for brain death and cardiac death, or on organ donor end-of-life care and the changes that would be needed if the patient was to be an organ donor. Few states disclosed that additional medical tests were necessary and that confidential medical records would be disclosed to organ procurement organizations. On the other hand, the websites included information about altruistic reasons to donate, claims that the family's grief is alleviated by donation, religious views condoning donation, and other positive affirmations. The authors concluded:
Our findings showed that the disclosure on OPO [organ procurement organization] Web sites and in online consent forms lacked pertinent information required for informed enrollment for deceased organ donation [...] The Web sites predominantly provide positive reinforcement and promotional information rather than the transparent disclosure of [the] organ donation process. ${ }^{87}$

Finally, mass media campaigns directed toward convincing people to donate organs have been similarly criticized for conflicts of interest and failing to disclose unbiased information that is relevant to making an informed decision about organ donation. ${ }^{88,89}$

There are significant controversies over whether brain death is truly death and thus whether heart-beating organ procurement kills the donor. Honesty, respect for persons, and respect for democratic procedures all seem to demand the widespread dissemination of these controversies in order to allow for a robust and transparent public debate about an issue that is of clear moral and democratic concern, and in order to allow for informed personal medical decision-making. On the other hand, it is not implausible that widespread dissemination of the academic controversies could have harmful consequences, particularly a reduction in organ donation rates. ${ }^{90}$ This is a classic example of the conflict between truth and consequences that was described by Brock. ${ }^{91}$ Future bioethics scholarship must find a way to resolve this conflict, while giving due regard to the moral importance of both truth and consequences.

\section{Legal and public controversies}

In the USA, the determination of death by neurological criteria has been legally recognized for decades, and the law in this area seems well settled. ${ }^{17}$ However, there have been several recent controversies involving brain death and the courts, and these have contributed to the increased attention paid to brain death in both scholarly and public discourse. I will briefly review three cases, which illustrate some of the controversies described above: a family's refusing to accept brain death as death; pregnancy in brain death; and dispute about informed consent for organ retrieval. (See Pope ${ }^{17}$ for a comprehensive legal briefing on brain death in the USA, as well as his legal briefings on medical futility ${ }^{92}$ and organ donation ${ }^{93}$ which are also relevant.)

\section{Jahi McMath}

Jahi McMath, a 13-year-old girl, was admitted to Oakland Children's Hospital in California for a tonsillectomy and adenoidectomy for sleep apnea on December 9, 2013. 
Due to complications after the surgery, she suffered from heavy bleeding in the throat, lost her airway, and suffered from anoxic brain injury. She was declared brain dead on December 12, 2013 after examination by two physicians. However, her parents did not accept the diagnosis. After the hospital informed the parents of their intention to discontinue mechanical ventilation, the parents obtained legal counsel and initiated legal proceedings in an effort to block the hospital from discontinuing ventilator support against their wishes.

The parents argued that they would not accept that Jahi was dead while her heart continued to beat. They also argued that the California statute defining death by neurological criteria was unconstitutional because it violated their religious beliefs. The Alameda County Superior Court did not rule on the merits of either of these claims. However, the court did manage to broker an agreement between the hospital and the parents, so that Jahi was declared legally dead by the hospital and released to the coroner, and then the coroner released her to the family. Jahi was eventually transferred to Saint Peter's Hospital in New Jersey, ${ }^{2,3,17}$ and as of March 6, 2015, she is residing in an apartment with home ventilator care in New Jersey, 15 months after the declaration of brain death. ${ }^{94}$

This case illustrates the concept and limits of "reasonable accommodation", in which patients (or their surrogates) object to neurological criteria for death and seek continued support after brain death. Given that death determined by neurological criteria is a legally valid determination of death, hospitals are not legally obliged to continue physiologic support of such patients. ${ }^{17}$ Physiologic support is usually only continued when the patient will be an organ donor, though many physicians and hospitals will voluntarily allow some additional time as a compassionate measure to help families cope with their grief. However, four states, New York, California, Illinois, and New Jersey, mandate accommodation of families or patients who object to the diagnosis of brain death. ${ }^{17}$

Both New York and California have regulatory requirements that mandate "reasonable accommodation" of families that object to the diagnosis based on moral or religious beliefs, but they do not spell out what constitutes "reasonable" or "accommodation", leaving individual hospitals to develop policies that will satisfy the regulations. Usually, this amounts to time for family members to gather at the bedside for a final visit before withdrawing support. Illinois's accommodation clause was enacted through its hospital licensing statute, ${ }^{95}$ and requires only that hospitals "adopt policies and procedures $[\ldots]$ to take into account the patient's religious beliefs concerning the patient's time of death". On the other hand,
New Jersey's brain death statute, the New Jersey Declaration of Death Act, ${ }^{96}$ includes a categorical exemption, in which a patient may not be declared dead based on neurological criteria if the attending physician has reason to believe that doing so would violate that patient's religious beliefs. This amounts to a mandate for indefinite accommodation for such patients. This categorical exemption for religious objections to brain death presumably means that, in New Jersey, she is not legally dead. ${ }^{17}$ As of July 2015 , the McMath case is still being litigated, with the family's attorney requesting that California rescind the death certificate. ${ }^{97}$

\section{Marlise Muñoz}

Marlise Muñoz, a 33-year-old woman, suffered a cardiac arrest from an apparent pulmonary embolism on November 26, 2013. Although her heartbeat was restored, she was determined to be dead by neurologic criteria soon after, at John Peter Smith Hospital in Texas. Her husband asked that she be removed from physiological support, but the hospital refused because she was 14 weeks pregnant at the time. The Texas Advance Directives Act ${ }^{98}$ like similar laws in several other states, includes a provision prohibiting the withdrawal of life-sustaining treatment from a pregnant patient. The hospital interpreted this law as applying to Mrs Muñoz, and thus refused to discontinue treatment. The husband filed a lawsuit, and the court ruled that the Texas Advance Directives Act did not apply because Mrs Muñoz had been determined to be legally dead. Thus, mechanical support could not be considered life-sustaining, and the court ordered the hospital to discontinue physiologic support, with which the hospital complied, though by that time 2 months had passed since her initial admission. ${ }^{2,3,17}$

This case illustrates the conceptual oddity of the brain death concept, in that an allegedly biologically dead body - a corpse - can gestate a living fetus, along with the predictable confusion generated by this seemingly paradoxical circumstance. Furthermore, in the husband's lawsuit, he alleged that the Texas Advance Directives Act violated equal protection under the law for pregnant women, since the right to refuse treatment was granted to some patients but not to pregnant women. ${ }^{3}$ Because the court ruled that the Texas Advance Directives Act did not apply, it never ruled on the crucial question of equal protection under the law for pregnant patients. Yet, presumably, the very same ethical considerations regarding precedent autonomy, surrogate decision-making, and the right to refuse treatment, would apply to Muñoz's case whether she had no brainstem reflexes, or just one, in which case she could not have been 
declared dead by neurological criteria, and the Texas Advance Directives Act would have applied.

\section{Elijah Smith}

Elijah Smith was a 22-year-old man who was hit by a car while riding a bicycle on July 3, 2013. He suffered from a severe head injury and was declared dead by neurological criteria the following day, at Grant Medical Center in Ohio. Mr Smith had previously registered as an organ donor when he applied for his driver's license. When he was determined to be dead by neurologic criteria, Grant Medical Center notified Lifeline of Ohio, the local organ procurement organization, which took steps to begin the process of organ procurement. However, his parents, Pamela and Rodney Smith, learned that organ removal takes place while the donor remains on mechanical ventilation during the surgery, and attempted to block Lifeline from removing Mr Smith's organs. According to Mrs Smith, her son did not understand what he was agreeing to when he registered as an organ donor, and that, had he understood that organ removal takes place while on a ventilator and with a beating heart, he would not have registered as a donor. ${ }^{99,100}$

Because of his parents' objections, Grant Medical Center denied Lifeline access to his organs without a court order. Lifeline subsequently obtained a court order from the Franklin County Probate Court, which was granted on the basis of Ohio law prohibiting anyone from reversing a donor's decision other than the donor. Mr Smith's organs were removed on July 11 over the objection of his parents.

According to the Columbus Dispatch, ${ }^{99,100}$ the Smith family wanted mechanical ventilation discontinued prior to organ removal. "We wanted for him to be unplugged, to see him die completely, so that we could accept that we did everything we could", Mrs Smith said. "If he did not continue breathing, then that would be how we would finally accept the fact that he was dead". Mrs Smith later described brain death as "a convenient way to facilitate the donation of [Mr Smith's] organs". However, "it's not that we're against organ donation", she said. "We just don't like the way it's done".

As this case illustrates, there is continued misunderstanding about the process of organ procurement after brain death, and this public misunderstanding can lead to confusion and, occasionally, conflict. Given the lack of information available on OPO websites, ${ }^{87}$ and the use of mass media campaigns as advertisements rather than information sources, ${ }^{88}$ it is unsurprising that Mrs Smith alleged that her son, like much of the general public, ${ }^{86}$ did not have a reasonable understanding of the circumstances of organ procurement to allow an informed choice, particularly when he registered as an organ donor by checking a box at a motor vehicle agency.

Laws recognizing the determination of death by neurological criteria are well established in the USA and throughout much of the world, and it is unlikely that such laws will soon be displaced. ${ }^{17}$ However, future developments may see additional reasonable accommodation requirements similar to those in California, New York, Illinois, and New Jersey. As Olick argued when the New Jersey brain death statute was passed in 1991, this approach may yet signal "a new direction for the development of public policy governing the declaration of death in pluralistic communities". ${ }^{101}$

\section{Conclusion}

The concept of brain death remains both settled and unsettled. The law and clinical practices in declaring death by neurological criteria are well established, and yet new controversies and challenges to both law and settled practice continue to surface. These controversies have taken on a new urgency in recent years, ${ }^{17}$ not only in academia, but also in the clinic, in the courtroom, and in the public arena. The status quo is one of "muddling through" in spite of long-known criticisms and controversies. It remains to be seen whether the recently increased scrutiny and debate signals the beginning of a fundamental reassessment of settled laws and practices, or if it is simply another phase of the same muddling through that has prevailed for decades, where brain death is paradoxically both well settled and persistently unresolved. ${ }^{53}$

\section{Disclosure}

The author reports no conflicts of interest in this work.

\section{References}

1. Wijdicks EF. Brain death worldwide: accepted fact but no global consensus in diagnostic criteria. Neurology. 2002;58(1):20-25.

2. Magnus DC, Wilfond BS, Caplan AL. Accepting brain death. $N$ Engl J Med. 2014;370(10):891-894.

3. Gostin LO. Legal and ethical responsibilities following brain death: the McMath and Munoz cases. JAMA. 2014;311(9):903-904.

4. Bernat JL. Whither brain death? Am J Bioeth. 2014;14(8):3-8.

5. Truog RD, Miller FG. Changing the conversation about brain death. Am J Bioeth. 2014;14(8):9-14.

6. Stevens ML. Redefining death in America, 1968. Caduceus. 1995;11(3): 207-219.

7. Jonsen AR. The Birth of Bioethics. Oxford: Oxford University Press; 1998.

8. Pernick MS. Brain death in a cultural context: the reconstruction of death, 1967-1981. In: Youngner SJ, Arnold RM, Schapiro R, editors. The Definition of Death: Contemporary Controversies. Baltimore: Johns Hopkins University Press; 1999:3-33.

9. De Georgia MA. History of brain death as death: 1968 to the present. J Crit Care. 2014;29(4):673-678.

10. Belkin GS. Brain death and the historical understanding of bioethics. J Hist Med Allied Sci. 2003;58(3):325-361. 
11. Belkin GS. Death Before Dying. Oxford: Oxford University Press; 2014.

12. Beecher HK. Ethical problems created by the hopelessly unconscious patient. N Engl J Med. 1968;278(26):1425-1430.

13. Mollaret P, Goulon M. [The depassed coma (preliminary memoir)] Rev Neurol (Paris).1959;101:3-15.

14. Ad Hoc Committee of the Harvard Medical School to Examine the Definition of Brain Death. A definition of irreversible coma. JAMA. 1968;205:337-340.

15. In re Quinlan. 70 NJ 10; 355 A.2d 647. 1976.

16. President's Commission for the Study of Ethical Problems in Medicine and Biomedical and Behavioral Research. Defining Death: Medical, Legal, and Ethical Issues in the Determination of Death. Washington, DC: US Government Printing Office; 1981.

17. Pope TM. Legal briefing: brain death and total brain failure. $J$ Clin Ethics. 2014;25(3):245-257.

18. Pallis C. ABCs of brain stem death: the position in the USA and elsewhere. Br Med J. 1983;286:209-210.

19. Royal College of Physicians. Criteria for the diagnosis of brain stem death. J R Coll Physicians Lond. 1995;29(5):381-382.

20. Lock M. Twice Dead: Organ Transplants and the Reinvention of Death. Berkeley and Los Angeles, California: University of California Press; 2002.

21. Elliot J. Brain death. Trauma. 2003;5:23-42.

22. Shemie SD, Hornby L, Baker A, et al. International guideline development for the determination of death. Intensive Care Med. 2014;40(6):788-797.

23. Smith M. Physiologic changes during brain stem death - lessons for management of the organ donor. $J$ Heart Lung Transplant. 2004;23(9 Suppl):S217-S222.

24. Smith M, Vyas H. Management of the potential organ donor. Paediatr Child Health (Oxford). 2010;21(4):182-186.

25. President's Council on Bioethics. Controversies in the determination of death: a white paper by the President's Council on Bioethics. Washington, DC; 2008.

26. Joffe AR. Limitations of brain death in the interpretation of computed tomographic angiography. Intensive Care Med. 2007;33(12):2218.

27. Wijdicks EF. The diagnosis of brain death. $N$ Engl J Med. 2001;344(16):1215-1221.

28. Wijdicks EF, Varelas PN, Gronseth GS, et al. Evidence-based guideline update: determining brain death in adults: report of the quality standards subcommittee of the American Academy of Neurology. Neurology. 2010;74(23):1911-1918

29. Varelas PN, Rehman M, Abdelhak T, et al. Single brain death examination is equivalent to dual brain death examinations. Neurocrit Care. 2011;15(3):547-553.

30. Wijdicks EF. The case against confirmatory tests for determining brain death in adults. Neurology. 2010;75(1):77-83.

31. Greer DM, Varelas PN, Haque S, et al. Variability of brain death determination guidelines in leading US neurologic institutions. Neurology. 2008;70(4):284-289.

32. Nair-Collins M, Northrup J, Olcese J. Hypothalamic-pituitary function in brain death: a review. J Intensive Care Med. Epub 2014 Mar 31. doi: 10.1177/0885066614527410.

33. Halevy A, Brody B. Brain death: reconciling definitions, criteria, and tests. Ann Intern Med. 1993;119:519-525.

34. Joffe AR, Anton NR, Duff JP. The apnea test: rationale, confounders, and criticism. J Child Neurol. 2010;25(11):1435-1443.

35. Coimbra CG. Implications of ischemic penumbra for the diagnosis of brain death. Braz J Med Biol Res 1999;32(12):1479-1487.

36. Tibbals J. A critique of the apneic oxygenation test for the diagnosis of "brain death". Pediatr Crit Care Med. 2010;11(4):275-278.

37. Lang CJ, Heckmann JG. Apnea testing for the diagnosis of brain death. Acta Neurol Scand. 2005;112(6):358-369.

38. Wijdicks EF, Rabinstein AA, Manno EM, Atkinson JD. Pronouncing brain death: contemporary practice and safety of the apnea test. Neurology. 2008;71(16):1240-1244.
39. Machado C, Perez J, Scherle C, Areua A, Pando A. Brain death diagnosis and apnea test safety. Ann Indian Acad Neurol. 2009;12(3):197-200.

40. Scott JB, Gentile MA, Bennett SN, Couture M, MacIntyre NR. Apnea testing during brain death assessment: a review of clinical practice and published literature. Respir Care. 2013;58(3):532-38.

41. Datar S, Fugate J, Rabinstein A, Couillard P, Wijdicks EF. Completing the apnea test: decline in complications. Neurocrit Care. 2014;21(3): 392-396.

42. Wijdicks EF, Pfeifer EA. Neuropathology of brain death in the modern transplant era. Neurology. 2008;70(15):1234-1237.

43. Karakatsanis KG. 'Brain death': should it be reconsidered? Spinal Cord. 2008;46(6):396-401.

44. Flowers WM, Patel BR. Persistence of cerebral blood flow after brain death. South Med J. 2000;93(4):364-370.

45. Truog RD, Robinson WM. Role of brain death and the dead-donor rule in the ethics of organ transplantation. Crit Care Med. 2003;31: 2391-2396.

46. Veatch RM. The whole-brain oriented concept of death: an outmoded philosophical formulation. J Thanatol. 1975;3:13-30.

47. Jonas H. Against the stream. In: Philosophical Essays: From Ancient Creed to Technological Man. Chicago: University of Chicago Press; 1980.

48. Lizza JP. Persons, Humanity, and the Definition of Death. Baltimore: The Johns Hopkins University Press; 2006.

49. Iltis AS, Cherry MJ. Death revisited: rethinking death and the dead donor rule. J Med Philos. 2010;35(3):223-241.

50. Miller FG, Truog RD. Death, Dying, and Organ Transplantation. Reconstructing Medical Ethics at the End of Life. New York, NY: Oxford University Press; 2012.

51. Nair-Collins M. Brain death, paternalism, and the language of "death". Kennedy Inst Ethics J. 2013;23(1):53-104.

52. Youngner SJ. Defining death. A superficial and fragile consensus. Arch Neurol. 1992;49:570-572.

53. Capron AM. Brain death - well settled yet still unresolved. $N$ Engl $J$ Med. 2001;344(16):1244-1246.

54. Truog RD. Brain death - too flawed to endure, too ingrained to abandon. J Law Med Ethics. 2007;35:273-281.

55. DeGrazia D. The definition of death. In: Zalta EN, editor. The Stanford Encyclopedia of Philosophy. Stanford University, Stanford, CA. 2011.

56. Green MB, Wikler D. Brain death and personal identity. Philos Public Aff. 1980;9(2):105-133.

57. Veatch RM. Abandon the dead donor rule or change the definition of death? Kennedy Inst Ethics J. 2004;14(3):261-276.

58. McMahan J. The Ethics of Killing: Problems at the Margins of Life. New York, NY: Oxford University Press; 2002.

59. Giacino JT, Fins JJ, Laureys S, Schif ND. Disorders of consciousness after acquired brain injury: the state of the science. Nat Rev Neurol. 2014;10(2):99-114.

60. Bernat JL. The whole-brain concept of death remains optimum public policy. J Law Med Ethics. 2006;34(1):35-43.

61. Bernat JL, Culver C, Gert B. On the definition and criterion of death. Ann Intern Med. 1981;94:389-394.

62. Bernat JL. The biophilosophical basis of whole-brain death. Soc Philos Policy. 2002;19(2):324-342.

63. Truog RD, Fackler JC. Rethinking brain death. Crit Care Med. 1992;20:1705-1713.

64. Shewmon DA. "Brainstem death," "brain death," and death: A critical re-evaluation of the purported equivalence. Issues Law Med. 1998;14(2): $125-145$.

65. Shewmon DA. Spinal shock and "brain death": Somatic pathophysiological equivalence and implications for the integrative-unity rationale. Spinal Cord. 1999;37:313-324.

66. Shewmon DA. The brain and somatic integration: Insights into the standard biological rationale for equating "brain death" with death. J Med Philos. 2001;26:457-478.

67. Powner DJ, Bernstein IM. Extended somatic support for pregnant women after brain death. Crit Care Med. 2003;31(4):1241-1249. 
68. Nair-Collins M. Taking science seriously in the debate on death and organ transplantation. Hastings Cent Rep. 2015;45:1-11. doi: 10.1002/ hast.459.

69. Bernat JL. A defense of the whole-brain concept of death. Hastings Cent Rep. 1998;28(2):14-23.

70. Miller FG, Truog RD. The incoherence of determining death by neurological criteria: a commentary on "Controversies in the determination of death", a White Paper by the President's Council on Bioethics. Kennedy Inst Ethics J. 2009;19(2):185-193.

71. Shah SK, Truog RD, Miller FG. Death and legal fictions. J Med Ethics. 2011;37:719-722.

72. Joffe A. Are recent defences of the brain death concept adequate? Bioethics. 2010;24(2):47-53.

73. Chiong W. Brain death without definitions. Hastings Cent Rep. 2005;35: 20-30.

74. Khushf G. A matter of respect: a defense of the dead donor rule and of a "whole-brain" criterion for determination of death. J Med Philos. 2010;35(3):330-364.

75. Veatch RM. The dead donor rule: true by definition. Am J Bioeth. 2003;3(1):10-11.

76. Shah SK, Miller FG. Can we handle the truth? Legal fictions in the determination of death. Am J Law Med. 2010;36(4):540-585.

77. Robertson JA. The dead donor rule. Hastings Cent Rep. 1999;29(6): 6-14.

78. Birch SC. The dead donor rule: a defense. J Med Philos. 2013;38(4): 426-440.

79. Brock DW. Voluntary active euthanasia. Hastings Cent Rep. 1992; 22(2):10-22.

80. Miller FG, Truog RD, Brock DW. Moral fictions and medical ethics. Bioethics. 2010;24(9):453-460.

81. Miller FG, Truog RD, Brock DW. The dead donor rule: can it withstand critical scrutiny? J Med Philos. 2010;35(3):299-312.

82. Miller FG, Truog RD. Rethinking the ethics of vital organ donations. Hastings Cent Rep. 2008;38(6):38-46.

83. Bernat JL. Life or death for the dead-donor rule? $N$ Engl J Med. 2013;369(14):1289-1291.

84. Nair-Collins M, Green SR, Sutin AR. Abandoning the dead donor rule? A national survey of public views on death and organ donation. J Med Ethics. 2015;41(4):297-302.

85. United Network for Organ Sharing (UNOS). Available from: https:// www.unos.org/. Accessed June 26, 2015.

86. Shah SK, Kasper K, Miller FG. A narrative review of the empirical evidence on public attitudes on brain death and vital organ transplantation: the need for better data to inform policy. J Med Ethics. 2015;41(4):291-296.
87. Woien S, Rady MY, Verheijde JL, McGregor J. Organ procurement organizations internet enrollment for organ donation: abandoning informed consent. BMC Med Ethics. 2006;7:14.

88. Rady MY, McGregor JL, Verheijde JL. Mass media campaigns and organ donation: managing conflicting messages and interests. Med Health Care Philos. 2012;15(2):229-241.

89. Rady MY, McGregor JL, Verheijde JL. Transparency and accountability in mass media campaigns about organ donation: a response to Morgan and Feeley. Med Health Care Philos. 2013;16(4):869-876.

90. DuBois JM. The ethics of creating and responding to doubts about death criteria. J Med Philos. 2010;35(3):365-380.

91. Brock DW. Truth or consequences: the role of philosophers in policymaking. Ethics. 1987;97(4):786-791.

92. Pope TM. Legal briefing: futile or non-beneficial treatment. J Clin Ethics. 2011;22(3):277-296.

93. Pope TM. Legal briefing: organ donation and allocation. J Clin Ethics. 2010;21(3):243-263.

94. Hutchinson D. Family of NJ girl declared dead files malpractice suit claiming hospital pressured them for organs. NJ.com; 2015. Available from: http://www.nj.com/somerset/index.ssf/2015/03/family_for_ jahi_mcmath_files_lawsuit.html. Accessed June 26, 2015.

95. The Hospital Licensing Act. 210 ILCS 85/6.24.

96. The New Jersey Declaration of Death Act. NJ Rev Stat $§ 26.6 \mathrm{~A}$ (1990).

97. Pope TM. Jahi McMath - a dispute over brain death. Available from: http://thaddeuspope.com/jahimcmath.html. Accessed July 24, 2015.

98. Texas Advance Directives Act. §672.002-672.013, THSC

99. Crane M. Dispute over organ donation brings attention to defining death. The Columbus Dispatch; 2013. Available from: http://www. dispatch.com/content/stories/local/2013/07/22/dispute-over-organdonation-brings-attention-to-defining-death.html. Accessed July 24, 2015.

100. Manning A. Family loses fight to keep son's organs from donation. The Columbus Dispatch; 2013. Available from: http://www.dispatch. com/content/stories/local/2013/07/11/Judge-ordered-family-to-letbrain-dead-son-donate-organs.html. Accessed July 24, 2015.

101. Olick R. Brain death, religious freedom, and public policy: New Jersey's landmark legislative initiative. Kennedy Inst Ethics J. 1991; 1(4):275-288.
Medicolegal and Bioethics

\section{Publish your work in this journal}

Medicolegal and Bioethics is an international, peer-reviewed, open access journal exploring the application of law to medical and drug research and practice and the related ethical and moral considerations. The journal is characterized by the rapid reporting of reviews, case reports, guidelines and consensus statements, original research
Dovepress

and surveys. The manuscript management system is completely online and includes a very quick and fair peer-review system. Visit http://www.dovepress.com/testimonials.php to read real quotes from published authors. 